\title{
Índice por temas 2021
}

\section{EDitoriales}

¿Qué hace la AAOT por mí?

Revista actual: evolución e incorporación

de editores de sección

Comité de Educación Médica Continuada.

Recuerdos para el futuro

Realidad actual. Lo que podemos aprovechar

Una deuda que saldar

¿Por qué publicar en la revista de la AAOT?

\section{INSTRUCCIÓN ORTOPÉDICA}

DE POSGRADO - IMÁGENES

Osteoporosis transitoria de la cadera 3 y 130

Mieloma múltiple. 138 y 281

Miositis osificante 289 y 437

Gonalgia. Linfoma óseo primario 444 y 560

Tendinopatía insercional reactiva posquirúrgica.

\section{TUMORES}

Normograma predictivo para evaluar la supervivencia en pacientes con metástasis vertebrales

Paraparesia aguda por hemangioma vertebral agresivo. Reporte de dos casos y revisión bibliográfica

Uso de denosumab para el quiste óseo aneurismático de columna. Reporte de un caso y revisión bibliográfica

\section{Columna}

Tratamiento mínimamente invasivo para fracturas toracolumbares
Fracturas de la columna vertebral en pacientes con espondilitis anquilosante

Descompresión lumbar en pacientes con enfermedad de Parkinson: serie de casos tratados con cirugía mínimamente invasiva

Evaluación de lesiones de la columna cervical en pacientes con politraumatismos, en el Servicio de Urgencias.

Técnica de "slalom" quirúrgico en estenosis de canal lumbar multinivel. Serie de casos tratados de manera simultánea con descompresión endoscópica y tubular con asistencia microscópica bilateral

Trauma medular cervical en pacientes con osificación del ligamento longitudinal posterior sin evidencia de fractura. Serie de casos y revisión bibliográfica

Lesiones medulares catastróficas en el rugby argentino. Impacto de las medidas implementadas y su reducción relativa en el tiempo.

Retiro de aguja intradural en la columna toracolumbar. Reporte de un caso .

Estudio de la anatomía sagital de la pelvis de pacientes con dolor sacroilíaco en el ámbito laboral.

Resultados del bloqueo epidural caudal en pacientes laboralmente activos con dolor lumbar.

\section{ORTOPEDIA INFANTIL}

Tenodermodesis para el tratamiento del dedo en martillo tendinoso de presentación tardía en niños y adolescentes

Traumatología infantil y COVID-19.

Experiencias en pandemia desde Córdoba,

Argentina

Análisis tomográfico de la alineación del retropié 
Resultados funcionales del tratamiento de coaliciones calcáneo-escafoideas con resección e interposición de grasa autóloga: Experiencia de dos centros

Seudoaneurisma cubital en un niño.

Reporte de un caso y revisión bibliográfica

Luxación aislada de codo en niños menores de 10 años: reporte de dos casos.

\section{Miembro SUPERIOR}

Reducción de la luxación de hombro en tiempos de pandemia. Una nueva luz sobre una vieja ventana

Artroplastia total de codo después de un proceso infeccioso. Cirugía en dos tiempos

Histología del bíceps en pacientes con tendinopatía crónica tratados con tenodesis subpectoral 246

Retorno al deporte luego de una cirugía de Latarjet: revisión sistemática de la bibliografía.

Osteotomía en cuña sustractiva supracondílea para el tratamiento del codo valgo del adulto

Prótesis total de codo en el contexto de una seudoartrosis de olécranon. Técnica quirúrgica y reporte de tres casos

Criterios radiográficos para la reducción rotatoria en fracturas diafisarias de húmero

Tratamiento con brace termoplástico para fracturas de húmero

Resultados del anclaje foveal artroscópico sin nudo del complejo del fibrocartílago triangular en lesiones Atzei 2/3

Resultados funcionales de las fracturas desplazadas del cuello del radio en niños: correlación entre las medidas de resultado informadas por el paciente (PROMIS y QuickDASH)

Resultados funcionales a largo plazo de la cirugía abierta de liberación del túnel carpiano

Mejoría del sueño en los pacientes operados por síndrome del túnel carpiano

Osteosíntesis en fracturas oblicuas o espiroideas largas de metacarpianos: comparación entre tratamiento con tornillos interfragmentarios solos y placa con tornillos
Luxofracturas radiocarpianas: evaluación retrospectiva de una serie de casos

Dedo azul agudo idiopático no isquémico: síndrome de Achenbach. Presentación de un caso y revisión bibliográfica.

Artroplastia interfalángica proximal de dedo de la mano con doble injerto osteocondral de costilla. Reporte de un caso y descripción de la técnica quirúrgica

Impactación cubitocarpiana

Reparación primaria de los flexores en la zona II. Actualización y técnica quirúrgica

Rehabilitación de los tendones flexores en la zona II. ¿Qué aspectos debemos tener en cuenta a la hora de abordar a los pacientes?

Revisión bibliográfica

Conducta en pacientes con parálisis y patología del nervio radial

Artroplastia invertida lateralizada para artropatía del manguito rotador en pacientes $>60$ años. Resultados y complicaciones a corto plazo

Lesiones de hombro atribuibles a la aplicación de la vacuna contra la COVID-19

Medición intraoperatoria con una aplicación para teléfono inteligente que mejora la precisión de las osteotomías desrotadoras

\section{MIEMBRo INFERIOR}

Estudio prospectivo de cirugía de hallux valgus con técnicas de Bösch y MICA. Análisis radiográfico comparativo a mediano plazo

Edema óseo secundario a lesiones ligamentarias de tobillo. Hallazgos en las imágenes de resonancia magnética

Estudio prospectivo comparativo del manejo de la analgesia preventiva en pacientes sometidos a artroplastia total de rodilla primaria

Implicancia de la radiografía con tracción y rotación interna en la evaluación de las fracturas de fémur proximal

Luxación periastragalina medial pura: reporte de casos y revisión bibliográfica 
Fascitis necrotizante como complicación de una osteosíntesis de fractura medial de cadera. Presentación de un caso

Fractura del poste tibial en la artroplastia total de rodilla estabilizada a posterior.

Presentación de dos casos

Tratamiento de las fracturas de cuello femoral con osteosíntesis. Diez claves para el éxito

Osteotomía percutánea de la falange distal

del hallux. Indicaciones y técnica

Evaluación de la estabilización de fracturas expuestas de pierna grados I y II de Gustilo en la etapa aguda

Vástagos estriados cónicos modulares en revisión de artroplastia total de cadera. Estudio multicéntrico. Resultados y complicaciones a mediano plazo.

Aloinjerto fresco de rótula y defectos osteocondrales.

Soporte circunferencial posterior en fracturas de platillo tibial

Artrosis rápidamente progresiva de cadera secundaria a una fractura por insuficiencia subcondral del acetábulo. Reporte de un caso

Osteomielitis de pubis. Reporte de caso 235

Paciente con síndrome de Klippel-Trenaunay. Reporte de un caso de reemplazo articular de cadera suspendido durante la cirugía

Actualización del tratamiento de las fracturas intertrocantéricas

Lesiones tendinosas del aparato extensor de la rodilla: Protocolo de tratamiento y rehabilitación

Prótesis unicompartimental lateral de rodilla en el tratamiento del genu valgo artrósico. Resultados en 29 artroplastias con un seguimiento promedio de 6.2 años

Artroscopia bilateral de rodilla en un solo tiempo quirúrgico, ¿es una opción segura?

Versatilidad del clavo endomedular retrógrado largo de tibia para artrodesis tibio-talo-calcánea en pacientes con lesiones asociadas en el mismo segmento
Tratamiento de la lesión aguda del tendón de Aquiles mediante una técnica mínimamente invasiva sin nudos. Rehabilitación y carga de peso inmediata.

Síndrome de Mazabraud: reporte de un caso 365

Técnicas de extracción de clavos endomedulares retrógrados de fémur rotos. Presentación de tres casos

Variantes quirúrgicas en el tratamiento de la desinserción proximal de isquiotibiales. Reporte de cuatro casos tratados con cirugía

Estudio retrospectivo comparativo entre aspirina y dabigatrán en la incidencia de eventos tromboembólicos en pacientes con artroplastia de cadera y rodilla

Comportamiento de los tallos no cementados recubiertos con hidroxiapatita colocados con alineación coronal inadecuada en la artroplastia primaria de cadera. Resultados del seguimiento a largo plazo.

Influencia de la fusión espinal en la orientación del implante acetabular

Análisis clínico-radiológico comparativo de tallos femorales no cementados planos de primera vs. segunda generación

Uso de conos de metal trabecular para defectos óseos severos en cirugía de revisión de reemplazo total de rodilla......

Comparación de los espaciadores articulados vs. fijos en la revisión de la infección periprotésica de rodilla.

¿Qué factores hacen fallar un reimplante de cadera luego de una revisión en dos tiempos?

Ventajas del abordaje externo para la artroplastia de rodilla por genu valgo severo

Reemplazo total de rodilla en pacientes con anquilosis. Reporte de tres casos y revisión bibliográfica

Colgajo neurocutáneo safeno y recambio de espaciador de cemento en el manejo de una artroplastia de rodilla infectada con defecto de cobertura cutánea. Reporte de un caso

Osteosíntesis en una fractura por estrés del pubis.

Reporte de un caso y revisión de la bibliografía 
Hematoma de Morel-Lavallée en la rodilla. Reporte de un caso

Reconstrucción del labrum de la cadera con injerto de ligamento redondo de la cabeza femoral.

Presentación de un caso y descripción

de la técnica quirúrgica

Impacto de la pandemia de la COVID-19 en el funcionamiento de un servicio público de Ortopedia y Traumatología: nuestro aprendizaje luego de la primera ola.

Osteotomía periacetabular de Ganz para el tratamiento de la displasia del desarrollo de la cadera: experiencia inicial y resultados de los primeros 44 casos

Tratamiento de las fracturas femorales periprotésicas Vancouver B3 con injerto óseo impactado.

Supervivencia y complicaciones .

Artroplastia total de rodilla después de una osteotomía tibial alta. Estudio retrospectivo comparativo entre osteotomías sustractivas y aditivas

Puntaje predictivo de resultado en la cirugía reconstructiva de miembros inferiores.

Ensayo preliminar

$40^{\circ}$ aniversario de una publicación introduciendo un implante aún vigente: "ENDO model"

\section{Temas Generales}

Uso de la matriz dérmica acelular para el tratamiento de zonas críticas en defectos de cobertura. Serie de casos

Evaluación de competencias clínicas y quirúrgicas de una Residencia de Ortopedia y Traumatología infantil. Utilización del Mini-CEX (Mini-Clinical Evaluation Exercise) y del DOPS (Direct Observation of Procedural Skills)
Hemicorporectomía y equipamiento protésico.

Reporte de un caso a los 15 años de seguimiento.

Deformidad de Gibbus no tuberculosa tratada con implante cubierto con nanopartículas de plata. Presentación de un caso

Colgajo perforante de la arteria circunfleja ilíaca superficial para la cobertura de defectos en los miembros

Datos epidemiológicos de lesiones en accidentes de tránsito. Encuesta del período enero 2017-julio 2020. Comité de Morbimortalidad AAOT

¿Cuál es el porcentaje de utilización de herramientas de evaluación de competencias quirúrgicas en las residencias de ortopedia y traumatología de la Argentina?

\section{ObituARIOS}

Profesor Dr. Héctor F. Girardi (1934-2020).

Celebración de vida.

Dr. Aroldo Carlos Legarreta (1955-2021)

Dr. Aníbal Julio Acuña. ¡Adiós Aníbal!

Dr. Franklin Merlo, Maestro de la Ortopedia

y Traumatología argentina

Fernando Silberman, "alma de docente"

Dr. Fernando Silvio Silberman (1930-2021)

Fe de ERRATAS

$285 ; 874$ 